\title{
MURILO MENDES, CRÍTICO DE ARTE
}

\author{
Lorenzo Mammì
}

Desde sempre, Murilo Mendes se interessou pelas artes plásticas. Só desenvolveu uma atividade constante de crítico, porém, depois da guerra, e sobretudo em Roma. Pode ter sido questão de ocasião, mas não só isso: é possível detectar uma maior densidade quantitativa e qualitativa do tema já nos textos da década de 1940 como veremos. É nessa fase, a meu ver, que o poeta começa a desenvolver uma reflexão critica consistente.

Numa primeira fase da produção de Mendes (até, digamos, Discípulo de Emaús, 1943), a arte desenvolve, de certa forma, o papel de duplo da poesia, ao mesmo tempo cúmplice e ameaçador. O lado ameaçador transparece com nitidez especial num poema juvenil, "O poeta na Igreja" (em Poemas, 1925-9): as formas são corpos, e os corpos são tentações. O artista nu é "sitiado pelas imagens exteriores", e não consegue "ultrapassar a linha dos vitrais". A transição do corpo da imagem, e deste à palavra, ao nome, é um movimento de progressiva transcendência. Mas a palavra não teria contundência, se não se encarnasse por meio da imagem, e essa encarnação implica, em geral, uma simpatia (ou compaixão, em sentido cristão) pelas pequenas existências, mas também um viés erótico que põe em perigo sua pureza. $\mathrm{O}$ movimento que, a partir da imagem, visa à transcendência é explicito em "Saudação a Ismael Nery" (Poemas): "Depois de fixar os contornos dos corpos / Transpõe a região que nasceu sob o signo do amor / E reúne num abraço as partes desconhecidas do mundo". Por outro lado, o viés carnal parece estabelecer analogias com a pintura de Cícero Dias: vejam-se não apenas "Glória de Cícero Dias" 
(Poemas), como também "Jandira” (O Visionário, 1930-33), onde, além da semelhança na maneira de encadear as imagens, o primeiro verso ("O mundo começava nos seios de Jandira”) talvez esconda uma referência à obra mais importante do artista pernambucano (Eu vi o mundo. Começava em Recife, 1929).

Contudo, essa abordagem, pela qual as artes plásticas são apenas um estágio intermediário numa elaboração contínua que vai dos corpos às palavras, não é certamente a ideal quando se trata de definir uma metodologia crítica específica. Em "Harpa-sofá (Um quadro de Vieira da Silva)" (Mundo Enigma, 1942), e sobretudo em "Vermeer de Delft" (Poesia Liberdade, 1943-5) a obra dos artistas não passa de um repositório de sugestões narrativas a serem retomadas em sede poética. É verdade que "Maria Vieira da Silva" (As Metamorfoses, 1938-41) faz referência à trama macia em que a pintora traduz a grade modernista, mas o faz injetando nela certa dose de surrealismo, que a torna dócil à invenção poética: "Bicho nervoso / Minucioso / Tece uma trama há mil anos / Que se transforma com a luz. / Em contraposto às formas / Da cidade organizada”.

Resta o caso de Goeldi. Há traços evidentes de influência do gravurista, por exemplo, em "Estudo quase patético" ( $O$ Visionário). Mas é significativo que a passagem que mais lembra a obra de Goeldi ("O temporal arranca os postes do lugar, / Os peixes pulam na atmosfera, / A luz elétrica protesta no caos".) tenha sido modifica na edição de 1959: originalmente, no lugar dos postes, havia taxis. Como se Mendes, conscientemente ou não, quisesse conferir a posteriori um ar mais goeldiano ao antigo poema.

A variante é tanto mais significativa, enquanto "Homenagem a Osvaldo Goeldi” (Parábola, 1946-52) é o poema de Mendes em que pela primeira vez pode se detectar uma mudança de postura crítica: ao poeta agora interessa não apenas o repertório de imagens, mas a praxe criativa do artista: "Não sujeitas o desenho à gravação: / Liberaste as duas forças. / Atingindo agora a unidade, / Pela natureza visionária / E pelo severo ofício / A tortura dominando, / Silêncio e solidão / Osvaldo gravas". E, sem nenhuma referência iconográfica, os versos têm a dureza enxuta da incisão de Goeldi, como os de juventude desdobravam a fluência fabuladora de Cícero Dias.

Um pouco antes, uma abordagem semelhante se encontra na obra em prosa, nos aforismos 339-59 do Discípulo de Emaús (1943) e, logo depois, se manifesta plenamente em Tempo Espanhol (1955-8), com os retratos de Velásquez, Goya, Picasso, Juan Gris e Joan Miró. João Cabral de Melo Neto (ao qual é dedicado Parábola) pode ter exercido certa influência 
nesse refinamento do instrumentário crítico, anterior à chegada à Itália. Ao contrário, não encontro similaridades entre a abordagem de Mendes e a de Mário Pedrosa, ao qual no entanto o poeta dedica $A$ invenção do finito (1960-70). É verdade que o gosto do Mendes, após a guerra, muda, e muda numa direção que o aproxima a Pedrosa: interesse pela arte informal e construtiva, abandono do surrealismo dos anos juvenis (a presença de Max Ernst e Giorgio De Chirico, nos Retratos-Relâmpago, 1965-6, é mais homenagem a influências do passado do que desdobramento de uma poética ainda atual). Mas as justificativas me parecem diferentes: Murilo Mendes não aparenta nenhum interesse numa análise gestáltica. No período italiano, a proximidade mais evidente, tanto na escolha dos autores quanto na dos argumentos, é com Giulio Carlo Argan, que escreveu o prefácio para a publicação póstuma de L'occhio del poeta. Em particular, é revelador o cotejo entre os textos críticos de Mendes e o livro em que Argan publicou, em 1977, os textos mais importantes de sua militância crítica nos anos de 1950 e 6o: Salvezza e caduta dell'arte moderna [Salvação e queda da arte moderna] (ARGAN, 1964).

No ensaio que dá o título ao livro, escrito em 1961, Argan propõe uma leitura das principais correntes artísticas da época (informalismo e neoconstrutivismo) divergente daquelas correntes. Segundo Argan, a situação contemporânea era caracterizada por dois aspectos: de um lado, a possibilidade real de aniquilação total da humanidade (estamos no auge da guerra fria) faz com que a salvação ou queda do gênero humano deixe de ser uma questão transcendente, da ordem da metafísica ou da religião, e se torne uma questão de escolha prática, cotidiana. Em outras palavras, desapareceria a distância entre finalidade última e ação imediata. A teleologia se torna imanente: toda ação é decisiva em si mesma, imediatamente, e não apenas porque se insere numa cadeia de ações visando um fim. O gesto do pintor informal, por exemplo, não remete a nada mais do que a si mesmo. Por isso, cada gesto se diferencia de todos os outros, mas, por ser um gesto isolado e sem consequências, é também igual a todos os outros, e forma com todos os outros uma massa indiferenciada - não faz história, para reaproveitar a terminologia de Argan. É assim que Argan interpreta Pollock: o dripping é o gesto absolutamente livre, aparentemente não condicionado, que porém só pode se repetir compulsivamente e se tornar, assim, estatístico. De resto, a afirmação de uma liberdade individual absoluta, mas indiferente, não relacionada a um fim, é segundo Argan, o fundamento de uma sociedade administrada.

O outro ponto que Argan salienta é que, no sistema industrial avançado, o fazer, como ato temporal que se esvaece continuamente, 
não encontra redenção num objeto finalmente realizado, que lhe confira permanência. No sistema de produção contemporâneo, ninguém é responsável senão por um segmento, e de resto os produtos não têm valor em si, mas só na medida em que realimentam a cadeia de produção e de consumo. Finalidade do sistema de produção tornou-se a reprodução e ampliação do próprio sistema. A utopia construtiva das décadas de 1920 e 1930, a que Argan aderiu em juventude, esperava transformar o sistema de produção a partir da racionalidade do objeto e com isso conferir aos artistas-designers, enquanto portadores de uma teoria da forma, certo controle sobre o sistema industrial. No segundo pós-guerra, essa ilusão já não é possível, justamente porque o objeto perdeu sua posição de centralidade no processo produtivo, e os designers (ou arquitetos, ou urbanistas) podem apenas operar na interface entre os polos de produção e consumo, nos quais já não interferem. A transformação do artista em técnico (na passagem da Bauhaus para a escola de Ulm) é consequência e sintoma dessa involução.

Cotejando as duas tendências (informal e neoconstrutiva), Argan aponta, portanto, para uma cisão fundamental: as técnicas tradicionais da arte (pintura, escultura, desenho etc.) tendem a se fundir entre elas, e não a se aprofundar cada um em sua especificidade, como queria Greenberg, mas, por outro lado, a se afastar sempre mais da relação com a produção dos objetos cotidianos, industriais, renunciando a agir sobre eles. Por sua vez, o neoconstrutivismo do pós-guerra perde os traços expressionistas e espiritualistas que ainda caracterizavam a produção da Bauhaus e do De Stijl, e sempre mais se torna aplicação técnica de princípios não problemáticos.

A questão, para Argan, é recuperar a função crítica que a arte detém desde o início da modernidade. Isso significaria que a arte, de forma análoga à filosofia, mas com uma metodologia e instrumentários diferentes, não resolveria, nem denunciaria, mas "demonstraria" os fundamentos da situação histórica atual. E o faria ao refletir sobre sua própria história, que Argan parece identificar com uma história da representação, não necessariamente de um referente externo, mas também de um fazer ou de um agir. Não se trataria, portanto, de escolher entre design técnico e gestualidade livre, mas revelar, na obra, a tensão entre os dois extremos, enquanto fundamento da situação artística contemporânea. Para tanto, me parece central, no pensamento de Argan, a noção de signo, oposto tanto ao gesto dos informais, quanto ao esquema dos neoconstrutivos: todo gesto, ou esquema, é também signo, enquanto remete a outra coisa além de si, e esse valor parece negado se levarmos às consequências extremas as duas tendências apontadas por Argan. 


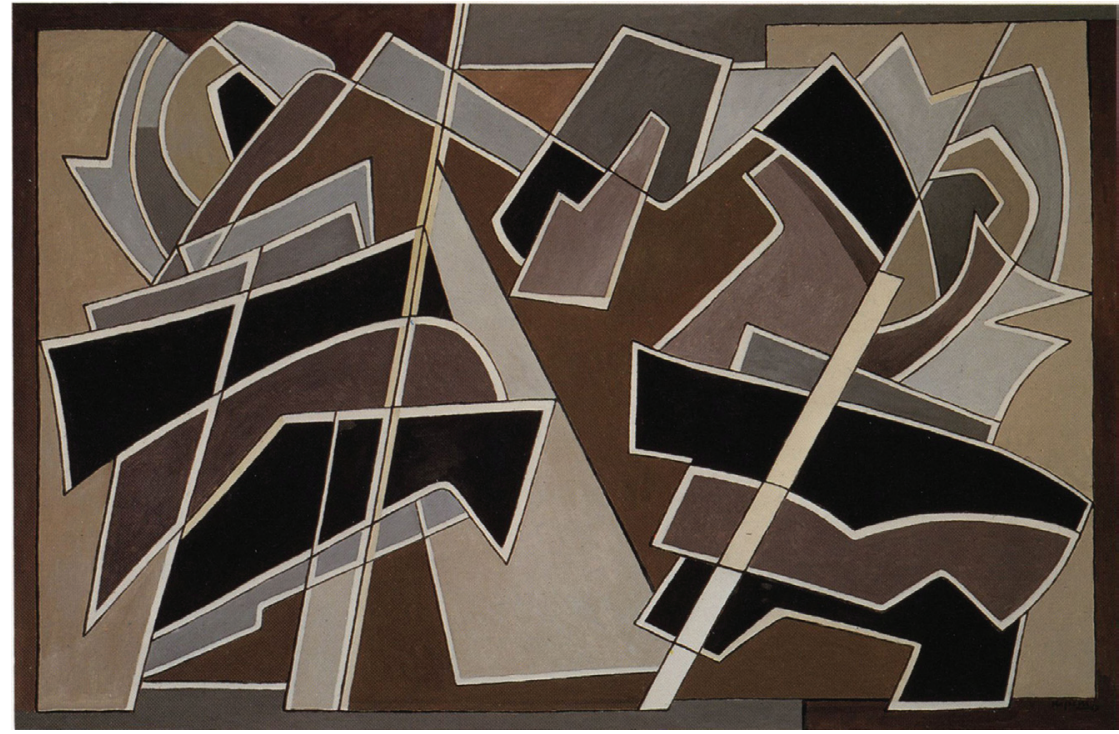

Alberto Magnelli, Tempête ordonnée, 1967

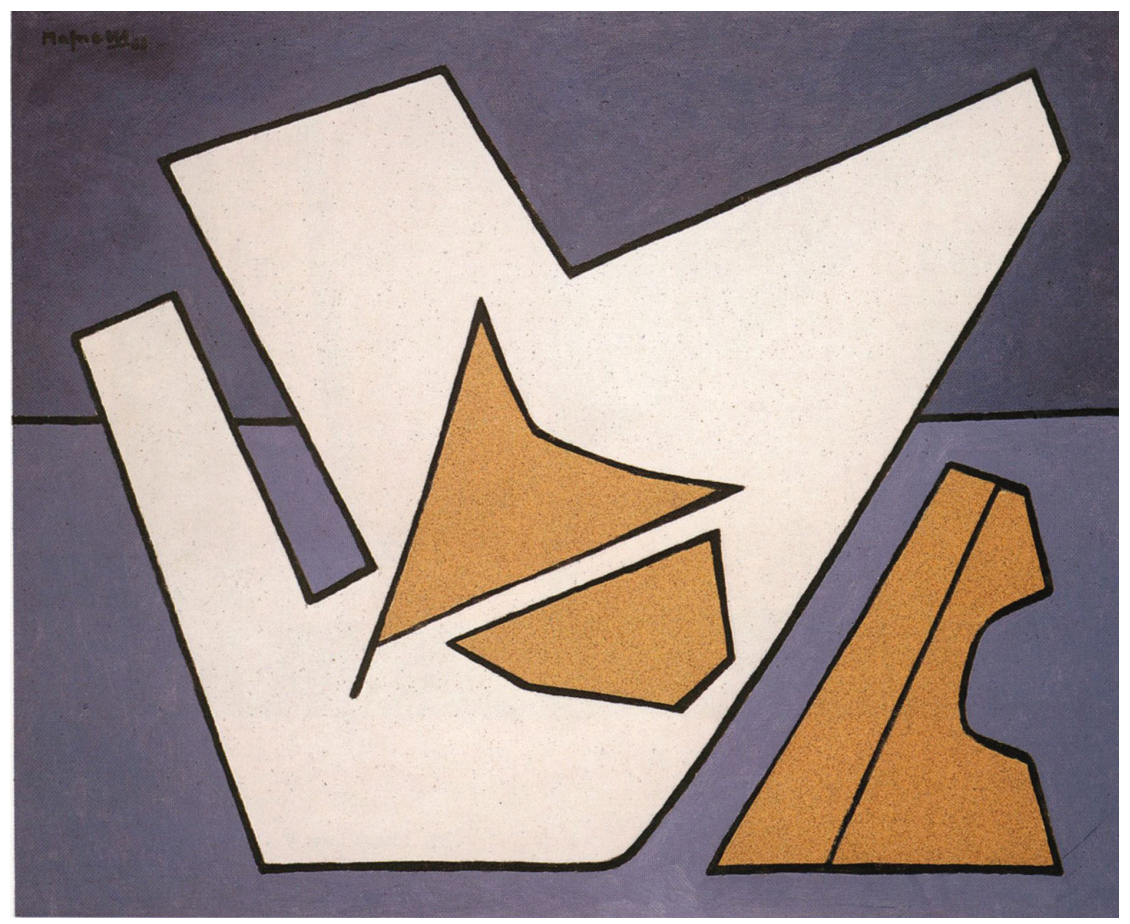

Alberto Magnelli, Dépasser le visuel, 1968 
Em Salvezza e caduta, Argan não propõe soluções, apenas assinala êxitos individuais (que são aqueles, justamente, em que o impasse é demonstrado com mais clareza). Num texto do ano seguinte, L' informale nella situazione odierna (1962), também incluído na coletânea, conclui, ao contrário:

A única solução possível da crise da arte contemporânea, no âmbito da situação geral da sociedade, é a solução da antítese informal-design; ou seja, a superação do mecanismo técnico e, portanto, do caráter abstrato da imagem do design mediante a experiência existencial do informal, ou a dissolução das duas polaridades opostas no plano concreto da vida. (ARGAN, 1964, p. 95. Trad do A.)

Gostaríamos de enxergar aqui uma antevisão das poéticas de identificação de arte e vida que seguirão daí a poucos anos, mas não é disso que se trata. Aliás, aqui está o limite da posição de Argan: na verdade, nesse período ele defende uma arte mais de compromisso do que de síntese. Os procedimentos tradicionais da arte (pintura, escultura etc.) são mantidos, e o estatuto da imagem não é alterado. Trata-se de recuperar, ao contrário, no gesto informal, uma noção de ordem, de discurso, de método, um repertório de signos que possa ser compartilhado. Nessa ótica, os artistas informais a que Argan dedica maior espaço são aquele em que é possível detectar algum tipo de controle e distanciamento crítico, e referências, ainda que esmaecidas ao extremo, à tradição modernista: Hans Hartung, Jean Fautrier, Mark Tobey.

Em Salvezza e Caduta, o vocabulário de Argan, marxista, é surpreendentemente religioso: salvação, queda, redenção, mito, ritual; até signo tem uma valência espiritual em algumas passagens. Isso já é um ponto de contato imediato com a sensibilidade de Mendes. Claro que os pontos de partida eram opostos: para Argan, os princípios éticos antigamente garantidos pela religião (em primeiro lugar a ideia de salvação) deveriam ser recuperados por um pensamento inteiramente voltado à imanência. Para Mendes, colocar no centro da reflexão a ideia de salvação significava reaproximar a arte da religião. Mas, no miúdo da atividade crítica, isso não fazia uma grande diferença. De fato, a proximidade entre Argan e Mendes é reconhecível imediatamente na escolha dos artistas. Em Salvezza e caduta, os artistas italianos abordados em textos monográficos, são nove: Magnelli, Vedova, Burri, Dorazio, Capogrossi, Corpora, Fontana, Leoncillo, Somaini. Seis deles (Magnelli, Vedova, Dorazio, Capogrossi, Corpora e Fontana) são objeto de textos 


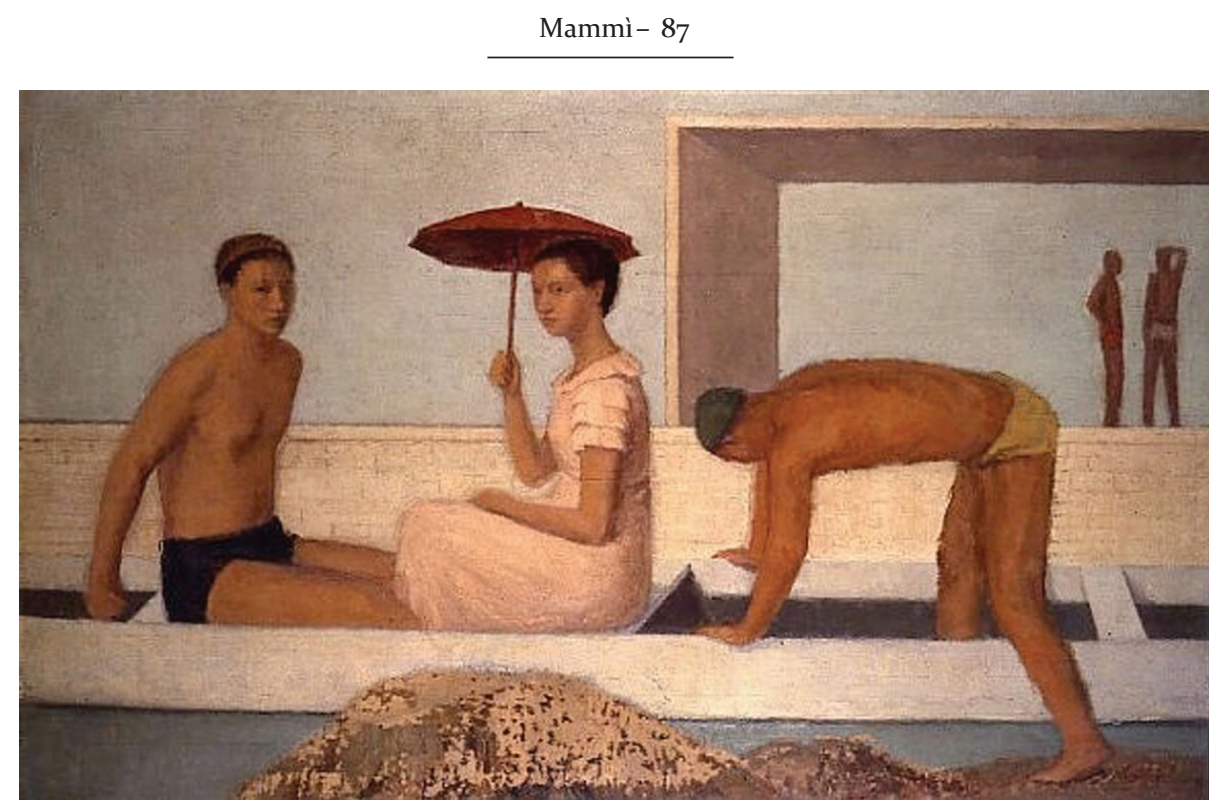

Giuseppe Capogrossi, I Canottieri, 1933 circa

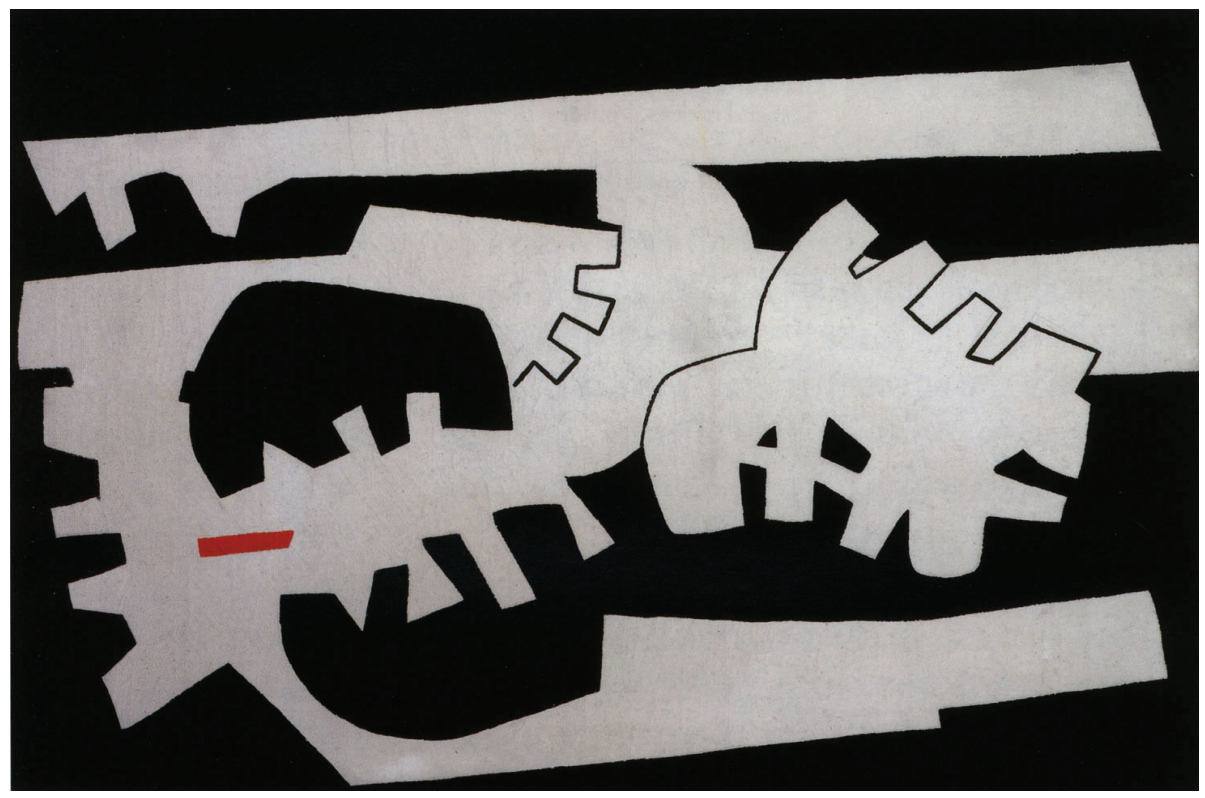

Giuseppe Capogrossi, Superficie 537, 1963 
críticos de Mendes, e às vezes de poemas. Não escreveu especificamente sobre Burri, que porém é lembrado com frequência nas resenhas sobre outros artistas, de maneira que podemos considerar essa ausência como meramente contingente. Os outros artistas comentados por Mendes pertencem aos mesmos movimentos ou defendem, em sua quase totalidade, poéticas parecidas.

A figura central é Alberto Magnelli. Foi um dos primeiros abstracionistas europeus, mas de um abstracionismo que não nasce de uma poética expressionista nem de uma esquematização geométrica, e sim da depuração de questões tradicionais da representação: relações entre figura e fundo, volume e plano, luz e cor etc. Argan salienta que as formas abstratas de Magnelli, aparentemente arbitrárias por não remeter a geradores geométricos, nascem justamente da análise da relação figura e fundo e da busca de situações limites entre a constituição do volume e sua dissolução no plano. Insiste também sobre a função do contorno marcado, característica de Magnelli, como uma espécie de rilievo schiacciato. Desenvolvendo esse tema, Mendes acentua a relação com o desenho, unido ao rebaixamento da cor, que seria uma característica "florentina” de Magnelli (citando, aliás, uma referência de Argan aos "mestres toscanos"), em oposição ao recurso a figuras geométricas e a cores puras de outras poéticas abstratas. Durante a guerra, Magnelli organizou um ateliê na Suíça, junto com Jean Arp, Sophie Tauber-Arp e Sonia Delaunay (Mendes escreveu sobre todos eles, menos Sophie Tauber-Arp). Depois da guerra, a exposição de Magnelli em 1947 em Paris teve uma enorme ressonância, comparável àquela de Picasso do mesmo ano, e marcou uma breve retomada da escola de Paris no cenário internacional. Depois de Ismael Nery, é certamente o artista que mais influência exerceu sobre as ideias estéticas de Murilo Mendes.

Outro conjunto consistente de artistas abordados por Argan e Mendes pertencia ao grupo Forma, que publicou seu manifesto no mesmo ano da exposição de Magnelli em Paris: 1947. O manifesto inicia assim:

Nós nos proclamamos FORMALISTAS e MARXISTAS, convencidos que os termos marxismos e formalismos não sejam inconciliáveis, especialmente agora que os elementos progressivos de nossa sociedade devem manter uma posição REVOLUCIONÁRIA e VANGUARDISTA e não se acomodar num realismo esgotado e conformista que nas mais recentes experiências em pintura e escultura já se revelou um caminho limitado e estreito. (Forma 1, 1947, p. 4. Trad. do A.) 
A polêmica imediata é, evidentemente, contra o realismo socialista, mesmo na versão italiana "modernizada" de Renato Guttuso e dos outros ex-integrantes do grupo Corrente. Contra essa tendência, apela-se para a tradição da vanguarda formalista, ou seja, para o construtivismo. Mas, como a forma deve se prestar a um engajamento político, ela vale enquanto signo, representação de um valor que tenha um conteúdo histórico. Isso é possível apenas se ela for vista não como um valor absoluto e eterno, mas como fruto de uma decantação que se dá na reflexão sobre a tradição da arte. De fato, o primeiro item defendido pelo grupo ("Em arte existe apenas a realidade tradicional e inventiva da forma pura") já coloca a forma pura no cruzamento de tradição e invenção, uma resumindo o passado, a outra olhando para o futuro. Com isso, o grupo se colocava numa linhagem de abstracionismo italiano que poderíamos chamar de historicista, cujas referências imediatas eram Magnelli e Gino Severini (sobre o qual Mendes também escreveu); mas também estabeleciam diálogo com o neocontrutivismo da Escola de Ulm. Os signatários do manifesto foram Carla Accardi, Ugo Attardi, Pietro Consagra, Piero Dorazio, Mino Guerrini, Concetto Maugeri, Achille Perilli, Antonio Sanfilippo e Giulio Turcato. Mendes dedicou textos ou poemas a cinco deles (Accardi, Dorazio, Perilli, Sanfilippo e Turcato). Dorazio, como vimos, é também tema de um ensaio em Salvezza e Caduta.

O grupo Forma teve bastante destaque na Itália do imediato pósguerra, sobretudo em Roma, e valeria a pena estudar a influência que podem ter exercido sobre o concretismo paulista, pela mediação de Waldemar Cordeiro, que estava em Roma na época. Contudo, sua postura não era bastante inovadora: substancialmente, defendia uma concepção tradicional do ofício do artista, dentro da prática do ateliê e das categorias tradicionais de pintura e escultura. As novas vanguardas de final de 1950 e da década de 1960 tornaram essa abordagem obsoleta.

Maiores consequências para a arte posterior tivera a atuação do grupo Origine. No manifesto de 1951, assinado por Mario Ballocco, Alberto Burri, Giuseppe Capogrossi e Ettore Colla, afirma-se a necessidade de reencontrar "o ponto de partida moralmente mais válido das exigências 'não figurativas' da expressão", mediante "a redução da cor à sua função expressiva mais simples, porém peremptória e incisiva; na evocação de núcleos gráficos, linearismos e imagens puras e elementares". Dos quatro artistas, Ballocco é quem teve menor ressonância. Nem Argan, nem Mendes escrevem sobre ele. Ettore Colla é escultor, de muita qualidade, que parte da escultura de solda de David Smith e de Júlio Gonzáles, mas desenvolve uma linguagem mais geométrica, baseando-se em geral em estruturas ortogonais. Alberto Burri e Giuseppe Capogrossi, por outro 
lado, estão entre os maiores artistas italianos da segunda metade do século XX.

A série dos Sacos de Burri consiste em trapos de juta colorida e costurada sobre o chassi para formar composições abstratas de extrema elegância formal. Nos Plásticos queimados o contraste entre o material de partida, vulgar até a abjeção, e a sedução visual do resultado é ainda mais acentuada. Argan afirmava que o problema central era superar a polarização entre a indiferença da técnica construtiva e a impotência do gesto informal, e julgava que isso só seria possível retomando a reflexão sobre a história da arte. Burri, sem retomar a questão literalmente (e talvez justamente por isso), foi provavelmente o artista que melhor respondeu ao desafio. Nele, a herança de uma tradição formal riquíssima se aplica a uma realidade que já não parece capaz de reagir, e quase se desfaz sob os olhos. Mas a matéria é significativa justamente por sua inércia, por não se deixar reduzir a forma exige ser reconhecida como o dejeto que ela se tornou. É Burri quem opera a transição entre certa tradição pictórica (sobretudo Morandi) e a Arte Povera.

Se o eixo do trabalho de Burri é a realidade dos materiais e a intensidade ética da cor, Giuseppe Capogrossi desenvolve o outro ponto levantado pelo manifesto (e talvez sugerido por ele): a identificação de núcleos gráficos elementares. Burri, médico de formação, começou a pintar apenas depois da guerra. Capogrossi era um artista com um percurso já relevante. Em 1933, foi um dos três signatários (com Roberto Melli e Emanuele Cavalli) do manifesto do Primordialismo plástico: uma pintura figurativa de formalismo muito acentuado e cores cuidadosamente compostas em gradações tonais, representando temas extraídos da vida cotidiana, aparentemente banais, mas revestidos de uma sacralidade vaga, como se as figuras estivessem cumprindo um ritual. De fato, as telas desta fase de Capogrossi aludiam a significados ocultos, inspirados no gnosticismo e nos mistérios antigos: suas cenas de praia, por exemplo, podem ser lidas como tantas etapas de um rito de iniciação. A partir de 1949, com uma virada surpreendente, Capogrossi reduziu sua pintura a variações infinitas de um único signo, uma curva cortada por traços, que lembra os símbolos cósmicos da pintura neolítica.

No texto destinado a uma exposição do artista, em 1962, Mendes defende a continuidade entre as duas fases: ao atribuir um significado arcano à banalidade moderna, Capogrossi buscava a origem de um encantamento com o mundo. No fim de sua viagem iniciática, encontra seu signo: "Transpostas as portas da noite o homem encontra o sol grande ícone abstrato”. Mendes recusa a identificação desse signo com 


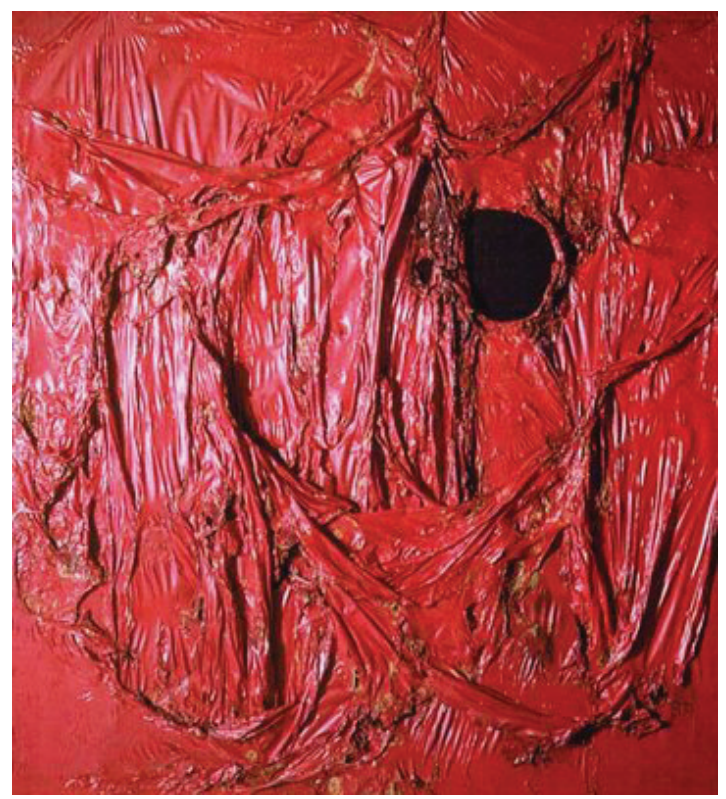

Alberto Burri, Grande Rosso, 1964

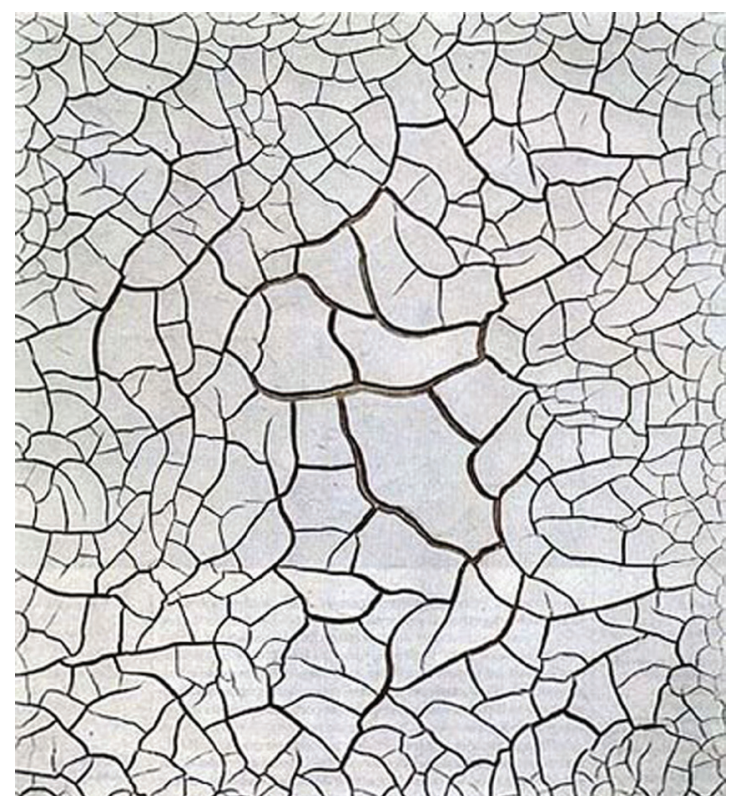

Alberto Burri, Cretto G1, 1975 
a arte pré-histórico. Prefere considerá-lo, se bem interpreto o texto, como sigla de uma interioridade que não pode ser mostrada, mas se desdobra exteriormente em movimentos que são mais da ordem do tempo do que do espaço - sucessões rítmicas que não definem lugares, mas durações. Encontrar seu próprio signo ("seu totem") significa resistir ao desaparecimento da individualidade. Mas desdobrá-lo no tempo significa desenvolver uma capacidade técnica, um metier. Na união entre a fórmula mágica e a prática artesã se encontra, segundo Mendes, o significado profundo da obra de Capogrossi.

A Capogrossi são dedicados também dois poemas. Afinal, a coerência de fundo entre as fases metafísica e abstracionista do artista chancelava uma leitura do abstracionismo que deixa espaço a certa sacralidade e justificava, por tabela, a evolução semelhante do crítico. Os textos não permitem afirmar com certeza que essa fosse a leitura de Mendes. Mas a poética de Capogrossi, como o vocabulário de Argan, ajudam a entender porque a sensibilidade religiosa do poeta se sentisse em casa no ambiente engajado e marxista do abstracionismo romano daqueles anos.

Nas poucas ocasiões em que promoveu e comentou exposições de artistas brasileiros, Mendes privilegiou aqueles que, mesmo adotando poética construtivas ou abstratas, preocupavam-se em relacioná-las com a tradição pictórica: Alfredo Volpi, em primeiro lugar; mas também o tonalismo de Arcângelo Ianelli. No caso de Franz Weissmann, são escolhidas não as obras mais claramente devedoras do construtivismo da escola de Ulm, mas as chapas amarrotadas, que tentam estabelecer um diálogo com as poéticas informais.

Como crítico, Murilo Mendes não pretende ser original: adere a um conjunto de ideias já bastante estabelecidas no ambiente romano daquela época, se filia a uma tendência em ato. Seus escritos críticos são exercícios de leitura e se apoiam explicitamente, inclusive por citações, a uma escola crítica determinada: Lionello Venturi, Giulio Carlo Argan, Nello Ponente. Desenvolvem-se como notas à margem que, no entanto, são muitas vezes precisas e preciosas. Além do texto sobre Capogrossi, vale ressaltar outro sobre Afro, um informalista italiano do qual Mendes soube enxergar com muita clareza, descendo no detalhe das telas, uma dialética entre tragédia e sedução que passara despercebida em outras leituras da época. Finalmente, não saberia encontrar mote melhor para todo esse movimento romano de artistas e críticos, empenhados em reduzir os gestos demasiados individuais dos informais e os esquemas demasiado universais dos neoconstrutivos a uma média que possa se constituir numa linguagem comum, do que o título que Murilo Mendes escolhe para sua antologia de críticas: $A$ invenção do finito. 


\section{REFERÊNCIAS BIBLIOGRÁFICAS}

ARGAN, Giulio Carlo. (1964). Salvezza e caduta nell'arte moderna. Milano: Il Saggiatore.

Forma 1. Mensile di Arti Figurative, Roma 15 mar 1947. 